\title{
A Novel Biomimetic Tool for Assessing Vitamin K Status Based on Molecularly Imprinted Polymers
}

\author{
Kasper Eersels $^{1}$ (D), Hanne Diliën ${ }^{1}$, Joseph W. Lowdon ${ }^{1}$, Erik Steen Redeker ${ }^{1}$ (D), \\ Renato Rogosic ${ }^{1}$, Benjamin Heidt ${ }^{1}$ (D), Marloes Peeters ${ }^{2}$ (D), Peter Cornelis ${ }^{3}$ (D), Petra Lux ${ }^{4}$, \\ Chris P. Reutelingsperger ${ }^{4}$, Leon J. Schurgers ${ }^{4}$ (D), Thomas J. Cleij ${ }^{1}$ (D) and Bart van Grinsven ${ }^{1, *}$ (iD \\ 1 Maastricht Science Programme, Faculty of Science and Engineering, Maastricht University P.O. Box 616, \\ 6200 MD Maastricht, The Netherlands; kasper.eersels@maastrichtuniversity.nl (K.E.); \\ hanne.dilien@maastrichtuniversity.nl (H.D.); joe.lowdon@maastrichtuniversity.nl (J.W.L.); \\ erik.steenredeker@maastrichtuniversity.nl (E.S.R.); renato.rogosic@maastrichtuniversity.nl (R.R.); \\ benjamin.heidt@maastrichtuniversity.nl (B.H.); thomas.cleij@maastrichtuniversity.nl (T.J.C.) \\ 2 Division of Chemistry and Environmental Science, School of Science and the Environment, \\ Faculty of Science and Engineering, Manchester Metropolitan University, Chester Street, \\ Manchester M1 5GD, UK; m.peeters@mmu.ac.uk \\ 3 Soft-Matter Physics and Biophysics Section, Department of Physics and Astronomy, KU Leuven, \\ Celestijnenlaan 200 D, B-3001 Leuven, Belgium; peter.cornelis@kuleuven.be \\ 4 Department of Biochemistry, Cardiovascular Research Institute Maastricht, Universiteitssingel 50, \\ 6200 MD Maastricht, The Netherlands; p.lux@maastrichtuniversity.nl (P.L.); \\ c.reutelingsperger@maastrichtuniversity.nl (C.P.R.); 1.schurgers@maastrichtuniversity.nl (L.J.S.) \\ * Correspondence: bart.vangrinsven@maastrichtuniversity.nl; Tel.: +31-(0)43-3882282
}

Received: 23 March 2018; Accepted: 8 June 2018; Published: 11 June 2018

\begin{abstract}
Vitamin K was originally discovered as a cofactor required to activate clotting factors and has recently been shown to play a key role in the regulation of soft tissue calcification. This property of vitamin $\mathrm{K}$ has led to an increased interest in novel methods for accurate vitamin $\mathrm{K}$ detection. Molecularly Imprinted Polymers (MIPs) could offer a solution, as they have been used as synthetic receptors in a large variety of biomimetic sensors for the detection of similar molecules over the past few decades, because of their robust nature and remarkable selectivity. In this article, the authors introduce a novel imprinting approach to create a MIP that is able to selectively rebind vitamin $\mathrm{K}_{1}$. As the native structure of the vitamin does not allow for imprinting, an alternative imprinting strategy was developed, using the synthetic compound menadione (vitamin $\mathrm{K}_{3}$ ) as a template. Target rebinding was analyzed by means of UV-visible (UV-VIS) spectroscopy and two custom-made thermal readout techniques. This analysis reveals that the MIP-based sensor reacts to an increasing concentration of both menadione and vitamin $K_{1}$. The Limit of Detection (LoD) for both compounds was established at $700 \mathrm{nM}$ for the Heat Transfer Method (HTM), while the optimized readout approach, Thermal Wave Transport Analysis (TWTA), displayed an increased sensitivity with a LoD of $200 \mathrm{nM}$. The sensor seems to react to a lesser extent to Vitamin E, the analogue under study. To further demonstrate its potential application in biochemical research, the sensor was used to measure the absorption of vitamin $\mathrm{K}$ in blood serum after taking vitamin $\mathrm{K}$ supplements. By employing a gradual enrichment strategy, the sensor was able to detect the difference between baseline and peak absorption samples and was able to quantify the vitamin $\mathrm{K}$ concentration in good agreement with a validation experiment using High-Performance Liquid Chromatography (HPLC). In this way, the authors provide a first proof of principle for a low-cost, straightforward, and label-free vitamin $\mathrm{K}$ sensor.
\end{abstract}

Keywords: thermal biosensor; vitamin K; synthetic receptors; HPLC validation 


\section{Introduction}

Synthetic receptors such as Molecularly Imprinted Polymers (MIPs) have gained interest in recent years, since these plastic antibodies mimic the affinity a natural receptor has for its target but overcome most of the disadvantages associated with their use [1,2]. Traditionally, MIPs were designed to act as a stationary phase in a wide variety of applications for affinity separation, utilizing the remarkable selectivity of these polymeric receptors to purify a compound of interest from a complex mixture [3-6]. In addition, MIPs have grown in popularity for their use as synthetic receptors in biomimetic sensors, owing to their low-cost and straightforward synthesis process [7], their unlimited shelf life [8], their chemical and thermal stability [9], and their robust nature [10].

Although MIP-based sensors for point-of-care diagnostics are not yet ready for the market, interesting progress is made in this field. MIPs have been combined with electrochemical transducers such as amperometry [11,12], cyclic voltammetry [13,14], potentiometry [15,16], or impedance spectroscopy [17-19] in a wide variety of sensor platforms. Alternative readout alternatives include optical or gravimetrical methods [20-23]. In 2012, the authors of this article introduced a thermal readout platform that monitors the thermal resistance of a chip, allowing for the identification of point mutations in DNA $[24,25]$. Over the years, this versatile transducer has been combined with various natural and biological receptors for the detection of cancer cells [26,27], bacteria [28,29], and proteins [30]. However, the combination with MIPs for the detection of small molecules has proven to be particularly interesting [31,32]. In a previous study, the thermal readout methodology has been improved by analyzing the propagation of a thermal wave rather than monitoring the thermal resistance at a constant input temperature, resulting in an improved sensitivity and reaction time $[29,33]$.

In this work, the authors have incorporated MIPs into a thermal biomimetic sensor platform for the selective detection of vitamin $\mathrm{K}$ in hexane-extracted blood serum samples. Vitamin K is very interesting from a medical point of view, as it plays an essential role in blood coagulation and regulates the calcification of bones, blood vessels, and other soft tissue [34]. Additionally, it functions as a co-factor in the post-translational carboxylation of several coagulation factors and regulatory proteins such as Matrix Gla Protein (MGP) and osteocalcin that regulate the mineralization of vascular tissue and bone respectively [34-36]. Phylloquinone or vitamin $K_{1}$ is the primary dietary form of vitamin $\mathrm{K}$ found in nature [37]. In adults, vitamin $K_{1}$ can be converted into vitamin $K_{2}$, a process that requires the intermediate vitamin $\mathrm{K}_{3}$ (menadione) [38]. Vitamin $\mathrm{K}_{2}$ accumulates in extrahepatic tissues, whereas $\mathrm{K}_{1}$ is the major hepatic form stored in the body [38]. As the concentration of phylloquinone in breast milk and the hepatic vitamin $\mathrm{K}$ reserve are low, breast-fed babies are at risk of developing vitamin $\mathrm{K}$ deficiency, leading to Vitamin K Deficiency Bleeding (VKDB) which can then lead to brain injury, death, or lifelong impairment [39]. This condition can be prevented by providing supplementary vitamin $\mathrm{K}_{1}$ to neonates. In adults, clinical vitamin $\mathrm{K}$ deficiency is rare as it is abundantly present in the human diet. However, in some cases (e.g., in patients suffering from cystic fibrosis liver damage, people undergoing dialysis) deficiency can arise [40-44], and low levels of vitamin K are associated with coagulopathy [45], osteoporosis [46], and coronary heart disease [47]. Accurately determining vitamin K status is costly, difficult, and often based on indirect tests that measure the amount of uncarboxylated osteocalcin, uncarboxylated MGP, or antagonism factor-II (PIVKA-II). Additionally, these tests are often based on laboratory techniques such as Enzyme-Linked Immuno Sorbent Assays (ELISA) [42,48], which require labeling. Direct measurements of fasting phylloquinone concentrations in plasma can be performed using reverse-phase liquid chromatography, a technique that requires expensive instrumentation, trained operators and a lab environment [49]. Therefore, a low-cost, label-free test that can determine the amount of vitamin K directly would be of great interest and help to the medical community.

The experiments described in this article provide a proof of concept for such a sensor platform. Methacrylic acid-based polymers were imprinted with the synthetic vitamin K compound menadione (vitamin $\mathrm{K}_{3}$ ). The structure of vitamin $\mathrm{K}_{3}$ is identical to that of the head group of its natural counterpart, but it lacks the long aliphatic side chain that would complicate imprinting. The authors hypothesized 
that the binding sites within the MIPs would be formed upon interaction with functional groups in the head group of the molecule, and the menadione-imprinted MIP should therefore be able to bind both the synthetic and the natural vitamin $\mathrm{K}$. The thermal analysis of the rebinding capacity of the MIPs confirms this hypothesis. The results obtained with non-imprinted reference electrodes and a study using vitamin $\mathrm{E}$ as an analogue indicate that rebinding is both selective and specific. The response was successfully quantified, and a detection limit of $200 \mathrm{nM}$ was established. In addition, the sensor was able to detect vitamin $\mathrm{K}$ in hexane-extracted blood serum samples drawn from one of the authors before and after ingestion of vitamin K-rich supplements. A progressive enrichment strategy was chosen to overcome the apparent limiting sensitivity of the readout technique.

\section{Materials and Methods}

\subsection{Chemicals}

Methacrylic Acid (MAA), chloroform, and aluminum oxide were purchased from Acros Organics. Methanol absolute, acetic acid, and toluene were bought from Biosolve Chimie SARL (Valkenswaar, The Netherlands). Phylloquinone (vitamin $\mathrm{K}_{1}$ ), PolyVinylChloride (PVC), and Menadione (vitamin $\mathrm{K}_{3}$ ) were supplied by Sigma-Aldrich (Zwijndrecht, The Netherlands). Acetone pure and Phosphate-Buffered Saline (PBS) tablets were purchased from VWR chemicals (Amsterdam, The Netherlands). Ethylene Glycol DiMethAcrylate (EGDMA) was procured from Merck Schuchardt OHG (Hohenbrunn, Germany). DL- $\alpha$-Tocopherol, 97+\% (Vitamin E) was supplied by Alfa Aesar (Karlsruhe, Germany). PolyDiMethySiloxane (PDMS) stamps were made with the Sylgard 184 elastomer kit from Mavom NV (Kontich, Belgium). Aluminum chips were purchased at Brico NV (Korbeek-Lo, Belgium) and cut to the desired dimensions.

\subsection{MIP Synthesis}

Stabilizers were removed from EGDMA and MAA by passing it over aluminum oxide. Due to its bulky, aliphatic, flexible side chain (Figure 1), phylloquinone (vitamin $\mathrm{K}_{1}$ ) is not suitable for imprinting. Therefore, menadione (vitamin $\mathrm{K}_{3}$ ) was used as a template in a dummy imprinting

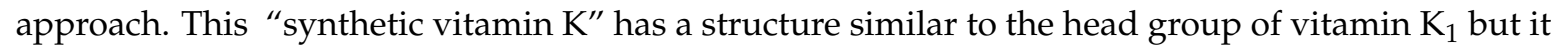
lacks the aliphatic chain. Vitamin $\mathrm{K}_{3}$ MIPs were synthesized by dissolving the functional monomer MAA (1.74 mmol), cross-linker molecule EGDM $(2.90 \mathrm{mmol})$, and initiator azobisisobutyronitrile (AIBN) $(50 \mathrm{mg})$ in dimethyl sulfoxide $(3 \mathrm{~mL})$ together with the menadione $(50 \mathrm{mg}, 0.29 \mathrm{mmol})$. The mixture was purged for $5 \mathrm{~min}$ with nitrogen gas to remove any oxygen or water from the mixture. Polymerization was thermally initiated at $65^{\circ} \mathrm{C}$ and the polymer was left to cross-link for $12 \mathrm{~h}$.

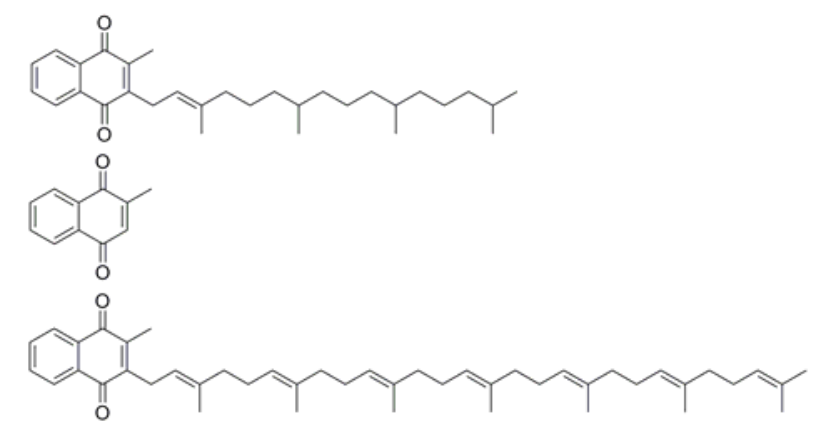

Figure 1. Chemical structure of Vitamin $K_{1}$ (upper figure), the synthetic analogue vitamin $\mathrm{K}_{3}$ (middle), and MK-7 (bottom).

Non-Imprinted Polymers (NIPs), serving as a reference, were made using the same protocol without including the target to the pre-polymerization mixture. MIPs and NIPs were milled seven times using a Fritsch Planetary Micro Mill Pulverisette 7 premium line (Idar-Oberstein, Germany) 
(700 rpm, $5 \mathrm{~min}, 10 \mathrm{~mm}$ balls) After milling, the particles were sieved at $1.0 \mathrm{~mm}$ amplitude using a Fritsch Analysette 3 for $4 \mathrm{~h}$ or until sufficient amount of polymer was on the collection plate and the $20 \mu \mathrm{m}$ sieve. The particles collected were between 20-45 $\mu \mathrm{m}$. Particle size was confirmed using a Scanning Electron Microscope (SEM, Philips XL 30Eindhoven, The Netherlands analysis shown in Supplementary Materials Figure S1). MIPs were extracted using a Soxhlet extraction procedure, in which MIPs were washed for $48 \mathrm{~h}$ with a 9:1 mixture of methanol and acetic acid, followed by a final extraction step with methanol during $24 \mathrm{~h}$. The polymers were dried at $65^{\circ} \mathrm{C}$ for $72 \mathrm{~h}$ prior to immobilizing them onto measurement chips.

\subsection{Chip Preparation}

Polished aluminum plates were cut to obtain chips with the desired dimensions $\left(10 \times 10 \mathrm{~mm}^{2}\right)$. To immobilize MIP particles, a $100 \mathrm{~nm}$ polyvinyl chloride (PVC) adhesive layer $(0.35 \mathrm{wt} \% \mathrm{PVC}$ dissolved in tetrahydrofuran) was deposited on the chip by spin coating at $3000 \mathrm{rpm}$ for $60 \mathrm{~s}$ with an acceleration of $1100 \mathrm{rpm} / \mathrm{s}$. MIP and NIP particles were stamped into this layer using a PDMS substrate that was covered with a monolayer of polymer particles. The PVC layer was heated for $2 \mathrm{~h}$ at a temperature above its glass transition temperature $\left(100{ }^{\circ} \mathrm{C}\right)$ allowing the beads to sink into the polymer layer. The samples were cooled down prior to thermal measurements and any unbound particles were washed off with distilled water.

\subsection{Sensing Setup}

The thermal detection platform is described thoroughly in previous work [31-33]. Functionalized chips were pressed mechanically with their backside onto a copper block serving as a heat provider. The temperature of the copper underneath the sample, $\mathrm{T}_{1}$, was monitored by a K-type thermocouple (TC Direct). This information was fed into a temperature control unit that stringently controlled $\mathrm{T}_{1}$ by modifying the voltage over the power resistor (Farnell, Utrecht, The Netherlands) that heats the copper, using a software-based (Labview, National Instruments, Austin, TX, United States) Proportional-Integral-Derivative (PID) controller $(P=10, I=5, D=0)$. The functionalized side of the chip faced a PolyEther Ether Ketone (PEEK) flow cell which was sealed with an O-ring to avoid leakage, defining a contact area of $28 \mathrm{~mm}^{2}$ and an inner volume of $110 \mu \mathrm{L}$. The flow cell is connected to a tubing system, allowing to exchange liquids in a controlled and automated fashion by means of a syringe pump. The temperature of the liquid inside the flow cell, $\mathrm{T}_{2}$, is measured by a second thermocouple placed $1 \mathrm{~mm}$ above the chip.

For each rebinding measurement, the signal was stabilized in acetonitrile which was used as a background solvent for the measurements, seeing as vitamin $\mathrm{K}$ does not dissolve in water. The concentration of the target or analogue inside the flow was gradually increased ( $50 \mathrm{nM}-2.25 \mu \mathrm{M})$. The signal was allowed to stabilize for $30 \mathrm{~min}$ between subsequent additions. Data were analyzed by monitoring the decrease in $\mathrm{T}_{2}$ after each addition (heat transfer method or HTM) while maintaining $\mathrm{T}_{1}$ at a constant $37.0{ }^{\circ} \mathrm{C}$. At the end of each stabilization platform, a thermal wave was sent through the chip with an amplitude at $0.1{ }^{\circ} \mathrm{C}$ and a variable frequency that increased from 0.01 to $0.05 \mathrm{~Hz}$. The transmitted wave was recorded and compared to the transmitted wave at baseline in terms of the observed phase shift and decrease in amplitude (Thermal Wave Transport Analysis, or TWTA).

\subsection{Proof of Concept}

To assess the sensor's potential for application in biochemical studies, an experiment was designed to verify whether it was possible to determine the difference between an extracted serum sample before and after vitamin $\mathrm{K}$ intake. Fasting blood was drawn from one of the authors in the morning to have a baseline condition for vitamin K. Following this, $5 \mathrm{mg}$ of MK-7 (menaquinone-7; kind gift of Nattopharma ASA, Hovik, Norway) was taken together with a breakfast low in vitamin $\mathrm{K}_{1}$ and $\mathrm{K}_{2}$, and blood was drawn $5 \mathrm{~h}$ after ingestion (known to be the peak absorption [50]). The serum was prepared and extracted with hexane and methanol. The water and methanol phase contains the 
water-soluble components and precipitated proteins. The hexane phase containing vitamin $\mathrm{K}$ was removed and evaporated under a constant stream of nitrogen at $37^{\circ} \mathrm{C}$, and the residue was dissolved in hexane. The hexane sample was divided and measured by TWTA and on conventional Reversed Phase (RP) HPLC. The study was conducted in accordance with the Declaration of Helsinki, and the protocol was approved by the Ethics Committee of Maastricht University Medical Center+.

The RP-HPLC detection method, based on fluorimetric detection after post-column zinc reduction, was introduced in previous work [50]. Briefly, after adding an internal standard (Vitamin $\mathrm{K}_{1}(25)$; a synthetic form of vitamin $\mathrm{K}_{1}$ containing 5 isoprenoid residues) to the sample, vitamin $\mathrm{K}$ was purified over Sep-pak cartridges and eluted from the silica with ether-hexane $(3: 97, v / v)$. The fraction containing vitamin $\mathrm{K}$ was concentrated by evaporating the hexane and reconstitute the residue with $0.2 \mathrm{~mL}$ isopropanol which was injected.

\section{Results and Discussion}

\subsection{Specific Detection of Vitamin $K_{3}$}

The HTM analysis of an experiment in which both a MIP-coated chip and a NIP-coated reference (Figure 2a) are exposed to vitamin $\mathrm{K}_{3}$ illustrate that the temperature inside the flow cell decreases with an increasing menadione concentration. These findings are in line with previously obtained results using MIP-based thermal sensors for the detection of neurotransmitters [31]. Binding the target into the binding cavities of the polymer particles increases the thermal resistance of the solid-liquid interface, impairing thermal transport into the flow cell. The data were used to construct a dose-response curve (Figure $2 b$ ). As the inter-sample variability on measurements done using three different samples from different batches was lower than the noise on the signal, the latter was used to construct the error bars. Both the error bars and average temperature were calculated over a period of $1000 \mathrm{~s}$. The data were fit in OriginPro 8 (OriginLabs Corporation, Northampton, MA, United States) using a dose-response fit for both the MIP (black curve, $R^{2}=0.9931$ ) and NIP electrode (red curve, $R^{2}=0.9541$ ). The blue dashed line indicates the value that corresponds to three times the maximum amount of noise on the signal throughout the measurement and its intercept with the linear part of the black curve predicts a preliminary Limit of Detection (LoD) of $700 \mathrm{nM}(3 \sigma$ method).

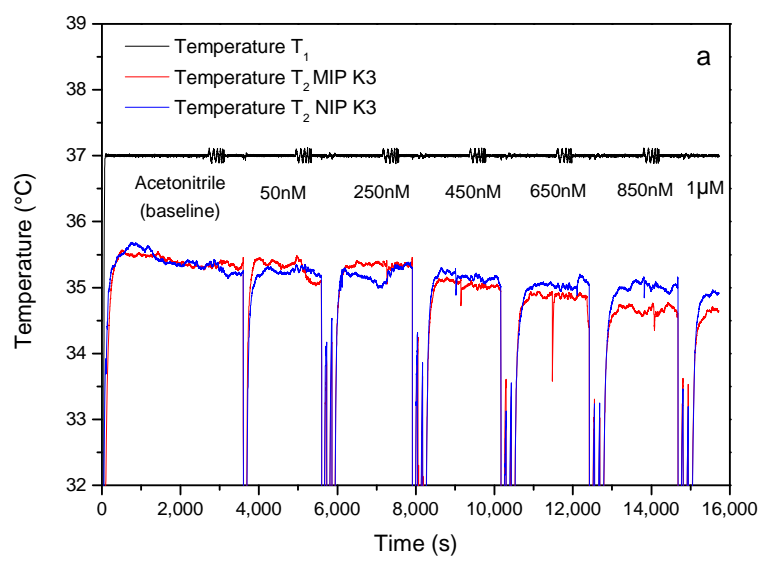

(a)

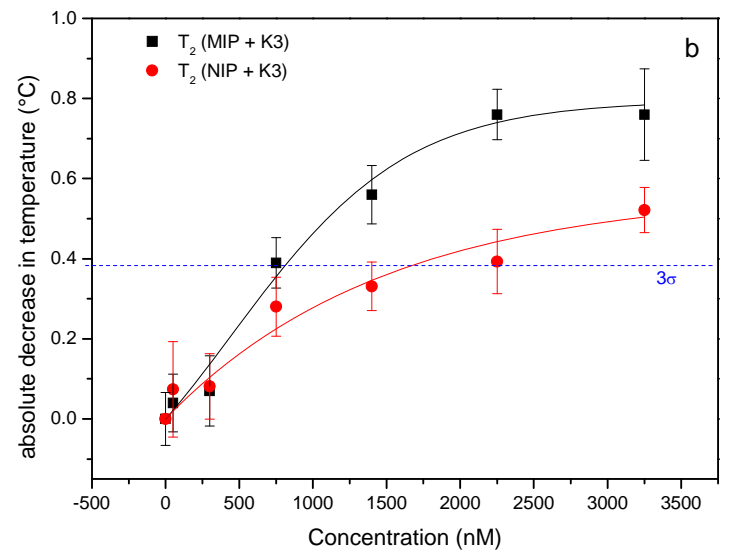

(b)

Figure 2. Heat-Transfer Method (HTM) analysis of a vitamin $\mathrm{K}_{3}$ rebinding experiment on Molecularly Imprinted Polymers (MIP) and a non-imprinted reference. (a) The time-dependent temperature profile shows that starting from a total concentration of $700 \mathrm{nM}$, the temperature inside the flow cell decreases as more vitamin $K_{3}$ is bound to the MIP. As the concentration of the target increases, the effect becomes more pronounced. (b) The dose-response curve reveals that the limit-of-detection (illustrated by the blue dotted 3 sigma line) is $\pm 700 \mathrm{nM}$. Non-imprinted polymer: NIP. 
In addition to HTM, the data were also analyzed using the TWTA method that has proven to be faster and more sensitive in previous research [33]. The results of this analysis (Figure 3a) show that the transmitted wave experiences a concentration-dependent phase shift. The increase in thermal resistance and thermal mass on the surface of the chip leads to an impaired transmission of the thermal wave, which can be observed as a phase shift and a decrease in the wave amplitude. The thermal wave Bode plot was calculated over a period of a $1000 \mathrm{~s}$ and reveals that an optimal resolution and effect size can be achieved at $0.03 \mathrm{~Hz}$ (Figure 3b), which confirms previous findings [33]. The Bode plot of the TWTA analysis using a NIP electrode (Figure 3c, wave analysis in Supplementary Materials Figure S2) reveals a similar behavior, but an imprinting factor between 1.7 and 2 can be observed over the entire concentration range, indicating that a significant part of the signal can be attributed to specific recognition of the target. The obtained data were used to construct a dose-response curve (Figure 3d) that corresponds well with the allometric dose-response fit that was applied for both the MIP (black curve, $R^{2}$ $=0.93711$ ) and the NIP electrode (red curve, $R^{2}=0.99685$ ). The LoD was calculated using the $3 \sigma$ method and was established at $200 \mathrm{nM}$. This improved sensitivity can be attributed to the fact that the noise on the transmitted wave in TWTA is much less pronounced. These findings are in line with results that were previously obtained for bacteria and dopamine detection [29,33]. All measurements were validated using a traditional batch rebinding experiment that is summarized in Supplementary Materials Figure S3.

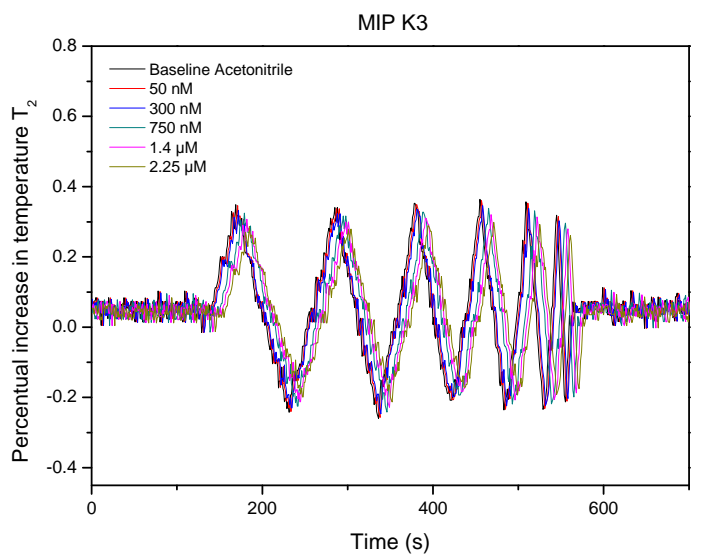

(a)

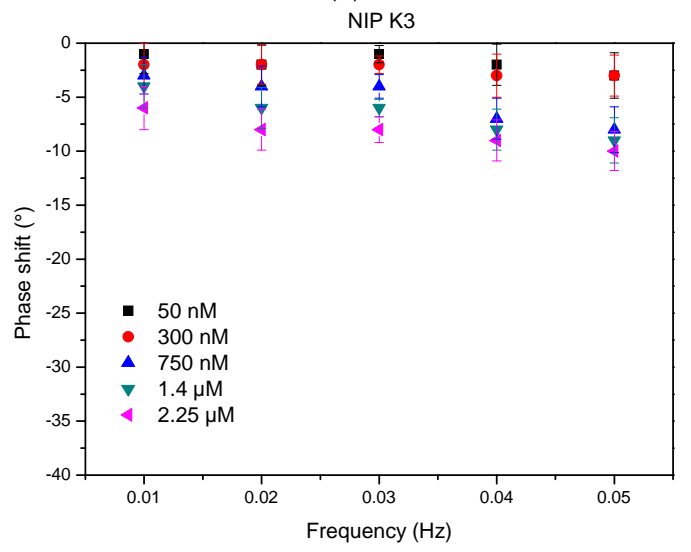

(c)

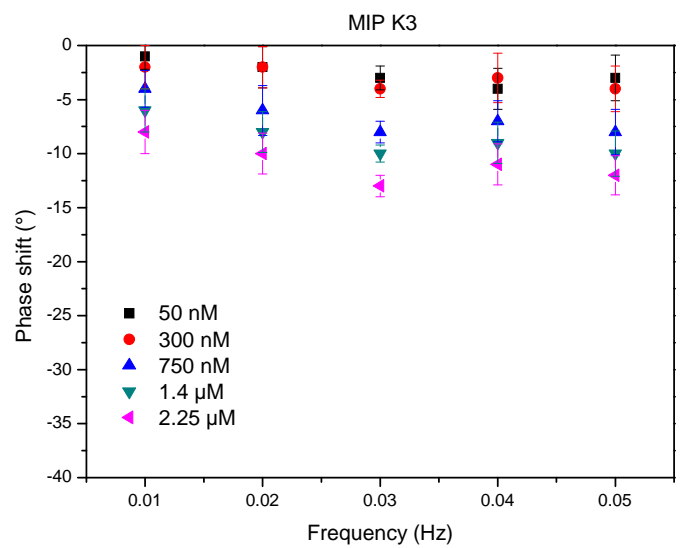

(b)

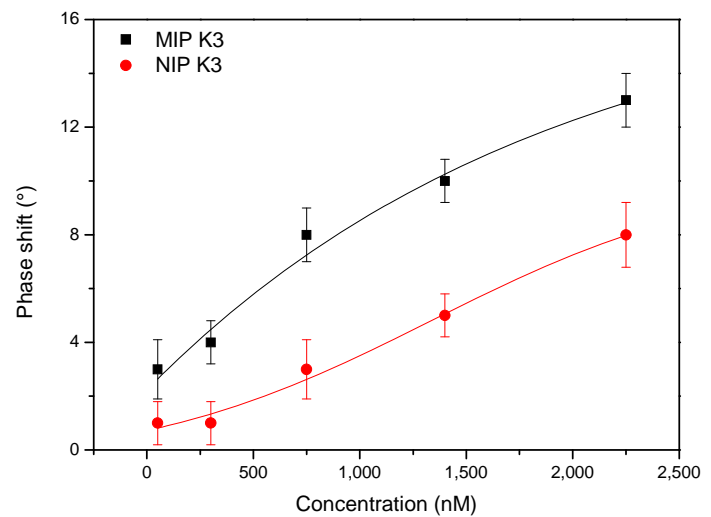

(d)

Figure 3. TWTA analysis of a vitamin $\mathrm{K}_{3}$ rebinding experiment on a MIP-coated electrode and a non-imprinted reference. (a) A delay on the transmitted wave and decrease in amplitude can be observed that increases as the concentration of target inside the flow cell increases. (b) The Bode plot indicates that the best concentration-dependent resolution is obtained at $0.03 \mathrm{~Hz}$. (c) The bode plot of the NIP shows a similar behavior but the effect size is lower. (d) The dose-response curve reveals that the limit of detection (illustrated by the blue dotted 3 sigma line) is in the $200 \mathrm{nM}$ range. 


\subsection{Vitamin $K_{1}$ Detection}

To test the hypothesis that MIPs imprinted with menadione should also be able to detect the natural vitamin $K_{1}$, vitamin $K_{3}$ MIPs and NIPs were immobilized onto aluminum chips and exposed to an increasing concentration of vitamin $\mathrm{K}_{1}$ in acetonitrile. The TWTA analysis (HTM analysis, wave spectrum, and Bode plots can be found in Supplementary materials Figure S4) reveals a dose-response curve at $0.03 \mathrm{~Hz}$ for vitamin $\mathrm{K}_{1}$, which is similar to that obtained for the template vitamin $\mathrm{K}_{3}$ (Figure 4 ).

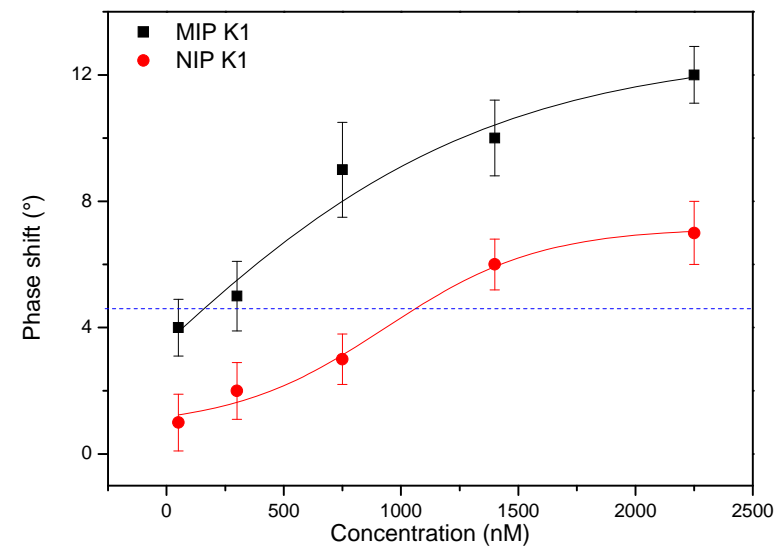

Figure 4. TWTA analysis of both a MIP, imprinted for vitamin $\mathrm{K}_{3}$, and NIP electrode exposed to an increasing concentration of vitamin $\mathrm{K}_{1}$ in acetonitrile. A concentration-dependent increase can be observed for both MIP (black curve) and NIP, but the imprinting factor varies between 1.5 and 2 over the entire concentration range. The dashed line represents the value corresponding to three times the maximal error on the signal. Its intercept with the dose-response fit for the MIP electrode defines a limit of detection in the range of $200 \mathrm{nM}$.

A concentration-dependent increase in phase shift is observed for both MIP and NIP over the entire concentration range, with imprinting factors varying from 1.5 to 2 . Although the maximum error on the signal for the vitamin $K_{1}$ measurements was slightly higher, resulting in a higher $3 \sigma$ value, the LoD was also established to be in the $200 \mathrm{nM}$ range. These findings confirm the hypothesis that imprints made by vitamin $K_{3}$ and vitamin $K_{1}$ are identical as the head group of vitamin $K$ is mainly responsible for the imprinting effect. The similar effect size observed in this experiment in comparison to the data in Figure 3 can be considered as somewhat surprising, seeing as vitamin $\mathrm{K}_{1}$ can only bind to the surface imprints on the MIP particles. However, the thermal resistance effects are mainly affected by changes happening at the surface boundaries that form the solid-liquid interface. In addition, binding the bulky Vitamin $\mathrm{K}_{1}$ to the receptor layer appears to increase both the thermal resistance and thermal mass at the solid-liquid interface to a larger extent than the smaller menadione molecule, compensating for the fact that it can only bind to the surface of the MIP particles.

\subsection{Selectivity Test}

The selectivity of the sensor was examined by exposing vitamin $\mathrm{K}_{3}$-imprinted electrodes to increasing concentrations of the analogue vitamin $\mathrm{E}$ ( $\gamma$-tocopherol) in acetonitrile, in a manner similar to the measurements described in the previous section, and comparing the response to that obtained with vitamin K. The HTM and TWTA analysis as well as the Bode plot can be found in the Supplementary Materials Figure S5. The TWTA response at $0.03 \mathrm{~Hz}$ was used to construct a dose-response curve that was compared to the dose-response curve for the MIP and NIP exposed to vitamin $\mathrm{K}_{1}$ (Supplementary Materials Figure S6). The data show that phase shift increases in function of the vitamin $\mathrm{E}$ concentration in the measuring cell. The data can be fitted using an allometric dose-response function $\left(R^{2}=0.99955\right)$ and demonstrate that most of the vitamin $\mathrm{E}$ binds in a non-specific manner to the functional interface as the response (blue curve) is nearly identical to that of an electrode coated with NIP particles (red curve) whereas 
the reaction of a MIP towards the target, vitamin $\mathrm{K}_{1}$, is a lot more pronounced (black curve). These findings illustrate that although the structure and size of $\gamma$-tocopherol and vitamin $\mathrm{K}_{1}$ are comparable, there is no specific interaction between the analogue and the binding sites created within the MIP particles. This further confirms the hypothesis that the head group of the template interacts with the forming polymer during formation and results in the formation of binding cavities that are able to selectively rebind vitamin $\mathrm{K}$.

\subsection{Proof of Application}

The hexane-extracted samples were analyzed using the MIP-based TWTA sensor system (Figure 5). Due to the low concentration of vitamin $\mathrm{K}$, a gradual enrichment strategy was employed. The MIP layer was exposed seven consecutive times to the same $3 \mathrm{~mL}$ sample by modifying the pumping system and creating a closed-circuit loop. As expected, the signal gradually increases for both the baseline and the five-hour sample. After three exposure runs, a significant phase shift ( $3 \sigma$ method) of $6.5 \pm 1.1^{\circ}$ can be observed for the five-hour sample. This falls within the relevant, linear range of the calibration curve and corresponds to a concentration of $593 \pm 80 \mathrm{nM}$, as calibrated from the MK-7 calibration curve shown in Supplementary Materials Figure S7. To calculate the original concentration, the linear part of the graph in Figure 5 was fitted, leading to a value of $1.595 \pm 1.1^{\circ}$ for the first exposure run, which corresponds to $145 \pm 80 \mathrm{nM}$. The same can be done for the baseline, although the signal barely reaches the significant level after five runs. The Vitamin $\mathrm{K}$ concentration $\mathrm{MK}-7$ and vitamin $\mathrm{K}_{1}$ in the baseline sample was analogously determined at $67 \pm 80 \mathrm{nM}$. The hexane samples were analyzed using HPLC, resulting in a total vitamin $\mathrm{K}$ content of $70.4 \mathrm{nM}$ in the sample that was taken $5 \mathrm{~h}$ after ingestion of MK-7, which corresponds well with the value obtained with the sensor. The baseline was determined at $3.3 \mathrm{nM}$ and therefore diverges from the sensor measurement by an order of magnitude. This can be explained by the fairly large error on the methodology in its present form. Even more interesting is the difference between the black and the red curve in Figure 5, which corresponds to a value of $64 \mathrm{nM}$ and should be caused by MK-7 intake. The HPLC was able to determine the MK-7 content in the hexane sample specifically and registered a value of $69 \mathrm{nM}$ for the five-hour sample and a concentration of $1.9 \mathrm{nM}$ in the baseline sample, corresponding to a difference of $67.1 \mathrm{nM}$. This striking agreement illustrates the potential use of TWTA in biochemical assays in the future, but must be looked at critically, since the error on the measurement is large.

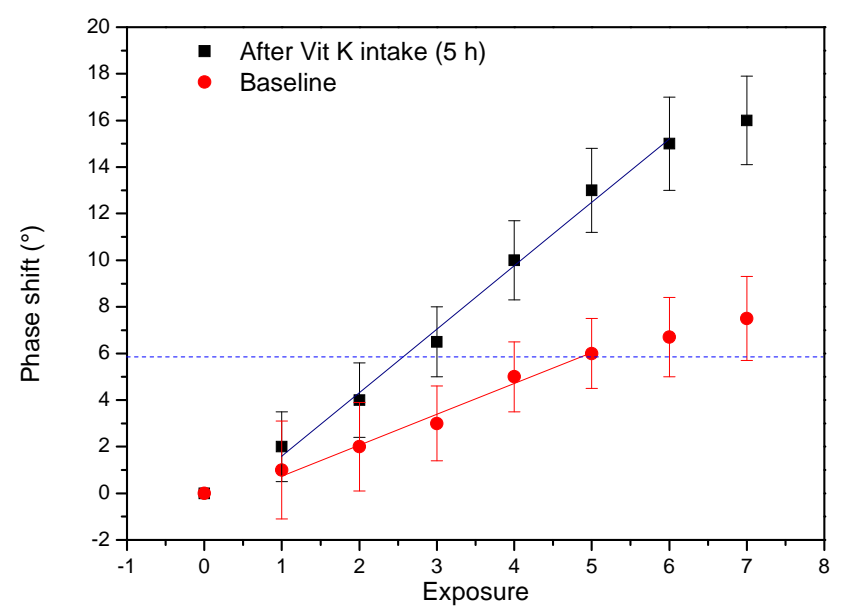

Figure 5. TWTA analysis of a blood serum sample before (baseline, red curve) and after ingestion of MK-7 tablets (black curve). A progressive enrichment strategy was applied for the $5 \mathrm{~h}$ sample that has an increasing effect on the signal with each exposure run. The blue line indicates the demarcation for a relevant increase in signal that is barely reached for the baseline, whereas a relevant concentration can be determined for the five-hour sample after three exposure runs and more. A linear fit was applied to determine the original concentration in the sample. 


\section{Conclusions}

Vitamin $\mathrm{K}$ is an essential dietary micro-nutrient, needed as an unequivocal cofactor in the activation of so-called vitamin $\mathrm{K}$ dependent proteins. With the discovery that vitamin $\mathrm{K}$ dependent proteins are involved in the inhibition of ectopic calcification, vitamin $\mathrm{K}$ has gained interest from both society and clinicians [51]. Traditional tests for assessing vitamin K concentrations include reversed-phase HPLC and mass spectrometry. These tests are expensive, labor-intensive, and time-consuming. This article describes the development of a MIP-based thermal biomimetic sensor that is able to selectively distinguish vitamin $K_{1}$ and vitamin $K_{2}$ (MK-7) from other vitamins using MIPs imprinted with the synthetic vitamin $\mathrm{K}$ analogue menadione. A proof of principle was established in this manner, demonstrating an MIP-based identification of vitamin $\mathrm{K}$ in acetonitrile. A preliminary limit of detection of $200 \mathrm{nM}$ was established for TWTA, whereas the original HTM appears to be a little less sensitive, which is in line with findings from previous studies. Although the sensitivity and selectivity of the synthetic receptor layers can still be optimized in the future, the gradual enrichment approach illustrates that it is possible to use the sensor to study the vitamin K content of blood serum samples with little sample pre-treatment needed. Improving the sensitivity of the platform by optimizing MIP synthesis and deposition and improving the sensor design to bring down the error on the measurement are both important next steps. It is however still necessary to study small physiological differences in vitamin K content that typically occur in the low nanomolar range.

Supplementary Materials: The following are available online at http:/ /www.mdpi.com/2072-6643/10/6/751/s1, Figure S1: SEM analysis of MIP particles, Figure S2: HTM analysis on both a MIP and a NIP electrode that are exposed to an increasing concentration of vitamin $\mathrm{K}_{1}$, Figure S3: UV-Vis batch rebinding analysis, Figure S4: TWTA analysis on both a MIP and a NIP electrode that are exposed to an increasing concentration of vitamin $\mathrm{K}_{1}$, Figure S5: HTM and TWTA analysis on both a MIP and a NIP electrode that are exposed to an increasing concentration of vitamin $K_{1}$ and vitamin E, Figure S6: TWTA analysis on a MIP exposed to an increasing concentration of vitamin E. (a) Wave analysis. (b) Bode plot, Figure S7: calibration curve for MK-7.

Author Contributions: The thermal wave transport device was designed by B.v.G. and T.J.C. TWTA measurements, data processing, and interpretation were performed by B.v.G., B.H., and K.E. The sensor setup and flow cell were redesigned by R.R. to allow for gradual enrichment experiments. All MIPs were synthesized by J.W.L., M.P, and H.D., and input on the synthesis and template removal protocol was provided by K.E., H.D., and T.J.C. Software design and programming were done by P.C and R.R. Input on possible medical and biotechnological applications and experimental design were provided by L.J.S., C.P.R., and E.S.R. Reference measurements and blood serum extraction were performed by P.L. in close cooperation with C.P.R. The manuscript was jointly written by K.E., L.J.S., and B.v.G. All authors have given approval to the final version of the manuscript.

Funding: This work was funded by the Province of Limburg through the Limburg Meet project (LiMe).

Acknowledgments: The authors are grateful for the financial support received from the Province of Limburg (LiMe). The authors would like to thank Katie Saralidze for the SEM analysis of the MIP particles, as well as Alejandra Monsegue, Lars van Turnhout, Ray Jayatunga, Kunsulu Nurekeyeva, Josh Frost, Jesko Wagner, Michael Jambor, Atte Rajahalme, Roxy Strijdhorst, and Yixiao Zhang for their support in the lab and MIP synthesis, extraction, milling, and sieving.

Conflicts of Interest: The authors declare no conflict of interest.

\section{References}

1. Wulf, G. Enzyme-like Catalysis by Molecularly Imprinted Polymers. Chem. Rev. 2002, 102, 1-28. [CrossRef]

2. Sellergen, B.; Allender, C.J. Molecularly Imprinted Polymers: A Bridge to Advanced Drug Delivery. Adv. Drug Deliv. Rev. 2005, 57, 1733-1741. [CrossRef] [PubMed]

3. Schirhagl, R.; Hall, E.W.; Fuereder, I.; Zare, R.N. Separation of bacteria with imprinted polymeric films. Analyst 2012, 137, 1495-1499. [CrossRef] [PubMed]

4. Qin, L.; He, X.W.; Zhang, W.; Li, W.Y.; Zhang, Y.K. Surface-Modified Polystyrene Beads as Photografting Imprinted Polymer Matrix for Chromatographic Separation of Proteins. J. Chromatogr. A 2009, 1216, 807-814. [CrossRef] [PubMed]

5. Cheong, W.J.; Yang, S.H.; Ali, F. Molecularly Imprinted Polymers for Separation Science: A Review of Reviews. J. Sep. Sci. 2013, 36, 609-628. [CrossRef] [PubMed] 
6. Liu, J.; Deng, Q.; Tao, D.; Yang, K.; Zhang, L.; Liang, Z.; Zhang, Y. Preparation of Protein Imprinted Materials by Hierarchical Imprinting Techniques and Application in Selective Depletion of Albumin from Human Serum. Sci. Rep. 2014, 4, 5487. [CrossRef] [PubMed]

7. Whitcombe, M.J.; Kirsch, N.; Nicholls, I.A. Molecular Imprinting Science and Technology: A Survey of the Literature for the Years 2004-2011. J. Mol. Recognit. 2014, 27, 297-401. [PubMed]

8. Chianella, I.; Guerreiro, A.; Moczko, E.; Caygill, J.S.; Piletska, E.V.; De Vargas Sansalvador, I.M.P.; Whitcombe, M.J.; Piletsky, S.A. Direct Replacement of Antibodies with Molecularly Imprinted Polymer Nanoparticles in ELISA-Development of a Novel Assay for Vancomycin. Anal. Chem. 2013, 85, 8462-8468. [CrossRef] [PubMed]

9. Haupt, K.; Mosbach, K. Molecularly Imprinted Polymers and Their Use in Biomimetic Sensors. Chem. Rev. 2000, 100, 2495-2504. [CrossRef] [PubMed]

10. Ye, L.; Haupt, K. Molecularly Imprinted Polymers as Antibody and Receptor mimics for Assays, Sensors and Drug Discovery. Anal. Bioanal. Chem. 2004, 378, 1887-1897. [CrossRef] [PubMed]

11. Ohnuki, H.; Saiki, T.; Kusakari, A.; Endo, H.; Ichihara, M.; Izumi, M. Incorporation of Glucose Oxidase into Langmuir-Blodgett Films Based on Prussian Blue Applied to Amperometric Glucose Biosensor. Langmuir 2007, 23, 4675-4681. [CrossRef] [PubMed]

12. Ramanaviciene, A.; Ramanavicius, A. Molecularly Imprinted Polypyrrole-Based Synthetic Receptor for Direct Detection of Bovine Leukemia Virus Glycoproteins. Biosens. Bioelectron. 2004, 20, 1076-1082. [CrossRef] [PubMed]

13. Tabushi, I.; Kurihara, K.; Naka, K.; Yamamura, K.; Hatakeyama, H. Supramolecular Sensor Based on $\mathrm{SnO}_{2}$ Electrode Modified with Octadecylsilyl Monolayer Having Molecular Binding Sites. Tetrahedron Lett. 1987, 28, 4299-4302. [CrossRef]

14. Lakshimi, D.; Bossi, A.; Whitcombe, M.J.; Chianella, I.; Fowler, S.A.; Subrahmanyam, S.; Piletska, E.V.; Piletsky, S.A. Electrochemical Sensor for Catechol and Dopamine Based on a Catalytic Molecularly Imprinted Polymer-Conducting Polymer Hybrid Recognition Element. Anal. Chem. 2009, 81, 3576-3584. [CrossRef] [PubMed]

15. Lang, R.; Chen, L.; Qin, W. Potentiometric detection of chemical vapors using molecularly imprinted polymers as receptors. Sci. Rep. 2015, 5, 12462. [CrossRef] [PubMed]

16. Wang, Y.; Zhang, Z.; Jain, J.; Yi, J.; Mueller, S.; Sokolov, J.; Liu, Z.; Levon, K.; Rigas, B.; Rafailovich, M.H. Potentiometric Sensors based on based on Surface Molecular Imprinting: Detection of Cancer Biomarkers and Viruses. Sens. Actuators B Chem. 2010, 146, 381-387. [CrossRef]

17. Bajwa, S.Z.; Lieberzeit, P.A. Recognition principle of Cu2+-imprinted polymers-Assessing interactions by combined spectroscopic and mass-sensitive measurements. Sens. Actuators B Chem. 2015, 207, 976-980. [CrossRef]

18. Cai, D.; Ren, L.; Zhao, H.; Xu, C.; Zhang, L.; Ying, Y.; Wang, H.; Lan, Y.; Roberts, M.F.; Chuang, J.H.; et al. A Molecular-Imprint Nanosensor for Ultrasensitive Detection of Proteins. Nat. Nanotechnol. 2010, 5, 597-601. [CrossRef] [PubMed]

19. Peeters, M.; Troost, F.J.; Mingels, R.H.G.; Welsch, T.; van Grinsven, B.; Vranken, T.; Ingebrandt, S.; Thoelen, R.; Cleij, T.J.; Wagner, P. Impedimetric Detection of Histamine in Bowel Fluids Using Synthetic Receptors with pH-Optimized Binding Characteristics. Anal. Chem. 2013, 85, 1475-1483. [CrossRef] [PubMed]

20. Altintas, Z.; Gittens, M.; Guerreiro, A.; Thompson, K.; Walker, J.; Piletsky, S.; Tothill, I.E. Detection of Waterborne Viruses Using High Affinity Molecularly Imprinted Polymers. Anal. Chem. 2015, 87, 6801-6807. [CrossRef] [PubMed]

21. Yilmaz, E.; Majidi, D.; Ozgur, E.; Denizli, A. Whole Cell Imprinting Based Escherichia coli Sensors: A Study for SPR and QCM. Sens. Actuators B Chem. 2015, 209, 714-721. [CrossRef]

22. Ratautaite, V.; Plausinaitis, D.; Baleviciute, I.; Mikoliunaite, L.; Ramanaviciene, A.; Ramanavicius, A. Characterization of Caffeine-Imprinted Polypyrrole by a Quartz Crystal Microbalance and Electrochemical Impedance Spectroscopy. Sens. Actuators B Chem. 2015, 212, 63-71. [CrossRef]

23. Hayden, O.; Dickert, F.L. Selective Microorganism Detection with Cell Surface Imprinted Polymers. Adv. Mater. 2001, 13, 1480-1483. [CrossRef] 
24. Van Grinsven, B.; Vanden Bon, N.; Strauven, H.; Grieten, L.; Murib, M.S.; Jimenez Monroy, K.L.; Janssens, S.D.; Haenen, K.; Schöning, M.J.; Vermeeren, V.; et al. Heat-Transfer Resistance at Solid-Liquid Interfaces: A Tool for the Detection of Single-Nucleotide Polymorphisms in DNA. ACS Nano 2012, 6, 2712-2721. [CrossRef] [PubMed]

25. Cornelis, P.; Vandenryt, T.; Wackers, G.; Kellens, E.; Losada-Pérez, P.; Thoelen, R.; De Ceuninck, W.; Eersels, K.; Drijkoningen, S.; Haenen, K.; et al. Heat Transfer Resistance as a Tool to Quantify Hybdrization Efficiency of DNA on a Nanocrystalline Diamond Surface. Diam. Relat. Mater. 2014, 48, 32-36. [CrossRef]

26. Eersels, K.; van Grinsven, B.; Ethirajan, A.; Timmermans, S.; Jiménez Monroy, K.L.; Bogie, J.F.J.; Punniyakoti, S.; Vandenryt, T.; Hendriks, J.J.A.; Cleij, T.J.; et al. Selective Identification of Macrophages and Cancer Cells Based on Thermal Transport through Surface-Imprinted Polymer Layers. ACS Appl. Mater. Interfaces 2013, 5, 7258-7267. [CrossRef] [PubMed]

27. Eersels, K.; van Grinsven, B.; Khorshid, M.; Somers, V.; Püttmann, C.; Stein, C.; Barth, S.; Diliën, H.; Bos, G.M.J.; Germeraad, W.T.V.; et al. Heat-Transfer-Method-Based Cell Culture Quality Assay through Cell Detection by Surface Imprinted Polymers. Langmuir 2015, 31, 2043-2050. [CrossRef] [PubMed]

28. van Grinsven, B.; Eersels, K.; Akkermans, O.; Ellermann, S.; Kordek, A.; Peeters, M.; Deschaume, O.; Bartic, C.; Diliën, H.; Steen Redeker, E.; et al. Label-Free Detection of Escherichia Coli Based on Thermal Transport through Surface Imprinted Polymers. ACS Sens. 2016, 1, 1140-1147. [CrossRef]

29. Steen Redeker, E.; Eersels, K.; Akkermans, O.; Royakkers, J.; Dyson, D.; Nurekeyeva, K.; Ferrando, B.; Cornelis, P.; Peeters, M.; Wagner, P.; et al. Biomimetic Bacterial Identification Platform Based on Thermal Wave Transport Analysis (TWTA) through Surface-Imprinted Polymers. ACS Inf. Dis. 2017, 3, 388-397. [CrossRef] [PubMed]

30. Peeters, M.; van Grinsven, B.; Cleij, T.J.; Jiménez-Monroy, K.L.; Cornelis, P.; Pérez-Ruiz, E.; Wackers, G.; Thoelen, R.; De Ceuninck, W.; Lammertyn, J.; et al. Label-free Protein Detection Based on the Heat-Transfer Method-A Case Study with the Peanut Allergen Ara h 1 and Aptamer-Based Synthetic Receptors. ACS Appl. Mater. Interfaces 2015, 7, 10316-10323. [CrossRef] [PubMed]

31. Wackers, G.; Vandenryt, T.; Cornelis, P.; Kellens, E.; Thoelen, R.; De Ceuninck, W.; Losada Pérez, P.; van Grinsven, B.; Peeters, M.; Wagner, P. Array Formatting of the Heat-Transfer Method (HTM) for the Detection of Small Organic Molecules by Molecularly Imprinted Polymers. Sensors 2014, 14, 11016-11030. [CrossRef] [PubMed]

32. Diliën, H.; Peeters, M.; Royakkers, J.; Harings, J.; Cornelis, P.; Wagner, P.; Steen Redeker, E.; Banks, C.E.; Eersels, K.; van Grinsven, B.; Cleij, T.J. Label-Free Detection of Small Organic Molecules by Molecularly Imprinted Polymer Functionalized Thermocouples: Toward In Vivo Applications. ACS Sens. 2017, 2, 583-589. [CrossRef] [PubMed]

33. Peeters, M.M.; van Grinsven, B.; Foster, C.W.; Cleij, T.J.; Banks, C.E. Introducing Thermal Wave Transport Analysis (TWTA): A Thermal Technique for Dopamine Detection by Screen-Printed Electrodes Functionalized with Molecularly Imprinted Polymer (MIP) Particles. Molecules 2016, 21, 552. [CrossRef] [PubMed]

34. Stenflo, J.; Fernlund, P.; Egan, W.; Roepstorff, P. Vitamin K Dependent Modifications of Glutamic Acid Residues in Prothrombin. Proc. Natl. Acad. Sci. USA 1974, 71, 2730-2733. [CrossRef] [PubMed]

35. Schurgers, L.J.; Uitto, J.; Reutelingsperger, C.P. Vitamin K-dependent carboxylation of matrix Gla-protein: A crucial switch to control ectopic mineralization. Cell 2013, 19, 217-226. [CrossRef] [PubMed]

36. Krueger, T.; Westenfeld, R.; Ketteler, M.; Schurgers, L.J.; Floege, J. Vitamin K deficiency in CKD patients: A modifiable risk factor for vascular calcification? Kidney Int. 2009, 76, 18-22. [CrossRef] [PubMed]

37. Schurgers, L.J.; Vermeer, C. Determination of phylloquinone and menaquinones in food. Effect of food matrix on circulating vitamin K concentrations. Haemostasis 2000, 30, 298-307. [PubMed]

38. Thijsen, H.H.; Vervoort, L.M.; Schurgers, L.J.; Shearer, M.J. Menadione is a metabolite of oral vitamin K. Br. J. Nutr. 2006, 95, 260-266. [CrossRef]

39. Sutor, A.H.; von Kries, R.; Cornelissen, E.A.; McNinch, A.W.; Andrew, M. Vitamin K deficiency bleeding (VKDB) in infancy. ISTH Pediatric/Perinatal Subcommittee. International Society on Thrombosis and Haemostasis. Thromb. Haemost. 1999, 81, 456-461. [PubMed]

40. Conway, S.P. Vitamin K in cystic fibrosis. J. R. Soc. Med. 2004, 97, 48-51. [PubMed] 
41. Westenfeld, R.; Krueger, T.; Schlieper, G.; Cranenburg, E.C.M.; Magdeleyns, E.J.; Heidenreich, S.; Holzmann, S.; Vermeer, C.; Jahnen-Dechent, W.; Ketteler, M.; et al. Effect of vitamin K2 supplementation on functional vitamin K deficiency in hemodialysis patients: A randomized trial. Am. J. Kidney Dis. 2012, 59, 186-195. [CrossRef] [PubMed]

42. Elliott, M.J.; Booth, S.L.; Hopman, W.M.; Holden, R.M. Assessment of potential biomarkers of subclinical vitamin $\mathrm{K}$ deficiency in patients with end-stage kidney disease. Can. J. Kidney Health Dis. 2014, 1, 13. [CrossRef] [PubMed]

43. Vossen, L.M.; Schurgers, L.J.; van Varik, B.J.; Kietselaer, B.L.J.H.; Vermeer, C.; Meeder, J.G.; Rahel, B.M.; van Cauteren, Y.J.M.; Hoffland, G.A.; Rennenberg, R.J.M.W.; et al. Menaquinone-7 Supplementation to Reduce Vascular Calcification in Patients with Coronary Artery Disease: Rationale and Study Protocol (VitaK-CAC Trial). Nutrients 2015, 7, 8905-8915. [CrossRef] [PubMed]

44. Peeters, F.E.C.M.; van Mourik, J.W.M.; Meex, S.J.R.; Bucerius, J.; Schalla, S.M.; Gerretsen, S.C.; Mihl, C.; Dweck, M.R.; Schurgers, J.L.; Wildberger, J.E.; et al. Bicuspid Aortic Valve Stenosis and the Effect of Vitamin $\mathrm{K} 2$ on Calcification Using ${ }^{18}$ F-Sodium Fluoride Positron Emission Tomography/Magnetic Resonance: The BASIK2 Rationale and Trial Design. Nutrients 2018, 10, 386. [CrossRef] [PubMed]

45. Alperin, J.B. Coagulopathy caused by vitamin K deficiency in critically ill, hospitalized patients. JAMA 1987, 258, 1916-1919. [CrossRef] [PubMed]

46. Katsuyama, H.; Ideguchi, S.; Fukunaga, M.; Saijoh, K.; Sunami, K. Usual dietary intake of fermented soybeans (Natto) is associated with bone mineral density in premenopausal women. J. Nutr. Sci. Vitaminol. 2002, 48, 207-215. [CrossRef] [PubMed]

47. Sano, M.; Fujita, H.; Morita, I.; Uematsu, H.; Murota, S. Vitamin K2 (menatetrenone) induces iNOS in bovine vascular smooth muscle cells: No relationship between nitric oxide production and gamma-carboxylation. J. Nutr. Sci. Vitaminol. 1999, 45, 711-723. [CrossRef] [PubMed]

48. Grundberg, C.M.; Nieman, S.D.; Abrams, S.; Rosen, H. Vitamin K status and bone health: An analysis of methods for determination of undercarboxylated osteocalcin. J. Clin. Endocrinol. Metab. 1998, 83, 3258-3266.

49. Davidson, K.W.; Sadowski, J.A. Determination of vitamin K compounds in plasma or serum by high-performance liquid chromatography using postcolumn chemical reduction and fluorimetric detection. Methods Enzymol. 1997, 282, 408-421. [PubMed]

50. Schurgers, L.J.; Teunissen, K.J.; Hamulyák, K.; Knapen, M.H.; Vik, H.; Vermeer, C. Vitamin K-containing dietary supplements: Comparison of synthetic vitamin K1 and natto-derived menaquinone-7. Blood 2007, 109, 3279-3283. [CrossRef] [PubMed]

51. Brandenburg, V.M.; Schurgers, L.J.; Kaesler, N.; Püsche, K.; van Gorp, R.H.; Leftheriotis, G.; Reinartz, S.; Koos, R.; Krüger, T. Prevention of vasculopathy by vitamin K supplementation: Can we turn fiction into fact? Atherosclerosis 2015, 240, 10-16. [CrossRef] [PubMed]

(c) 2018 by the authors. Licensee MDPI, Basel, Switzerland. This article is an open access article distributed under the terms and conditions of the Creative Commons Attribution (CC BY) license (http:/ / creativecommons.org/licenses/by/4.0/). 